\title{
MISCELLANEA
}

\section{Four Studies of the Relation between Psychological and Occupational Handicap among Industrial Workers}

\author{
ALASTAIR HERON \\ From the Medical Research Council Unit for Research in \\ Occupational Adaptation
}

In the last of the famous series of reports issued by the Industrial Health Research Board it was made clear that the valuable and interesting survey carried out by Russell Fraser and his colleagues (Fraser, 1947) was essentially psychiatric, as distinct from psychological, in approach and technique. When the Medical Research Council shortly afterwards decided to form the present Unit, provision was made from the outset ensuring that in the more intensive industrial surveys likely to occupy a section of the Unit for several years one or more psychologists would have an active part. The present paper reports the general outcome of that decision in a manner which it is hoped will prove sufficiently nontechnical to interest a wide audience. (The reader desiring more detailed information about the methods used is accordingly referred to a number of scientific papers quoted which contain full supporting evidence for the findings reported here.)

The studies to be described had a single objective : to demonstrate the extent, if any, to which psychological handicaps, such as inadequate general intelligence or emotional instability, are connected systematically with occupational handicap among industrial workers. Each study contributed to the design of the next, and together they represent an integrated programme of field research and related statistical evaluation carried out during the five years 1949 to 1954 in the north-west of England.

\section{Populations Studied}

The four populations were as follows :-

(1) Eighty men between the ages of 22 and 64 years, forming the entire population of a basic production department in a medium-sized factory. These men were unskilled workers on individual piecework who had been in the department concerned for periods ranging from one to 30 years, the median falling at 10 years. This group will henceforth be referred to as "the settled workers" (Heron, 1952a and b, 1954a).

(2) One hundred and eighty-four colliery workers between the ages of 40 and 50 years, of whom 76 spent their working time wholly underground, 25 partly underground and partly on the surface, 44 full-time on the surface as manual workers, and 39 in the colliery offices (Heron and Braithwaite, 1953).

(3) One hundred and twenty-four women between the ages of 16 and 57 years, who when seen had just become employed as unskilled workers in a wide variety of departments of a factory making electrical equipment. Reference is made opposite to two groups, described as the "older women" and the "younger women" respectively, the break occurring at 35 years (Heron, 1955b).

(4) One hundred and ninety-two men between the ages of 18 and 46 years, who without previous experience in similar work had just obtained employment as bus conductors with a large municipal undertaking (Heron, 1954b, 1955a ; Venables, 1953, 1955).

\section{Procedures Employed}

In all these studies, the task was to assess by objective means the extent of emotional instability in each subject, and, except in the case of the colliery workers, to obtain also an objective assessment of general intelligence. For this latter purpose use was made of tests of proven reliability and validity which had been found suitable for use with adults in other studies elsewhere. The assessment of emotional instability by objective means still represents a considerable technical problem, and all the procedures used were of a largely experimental kind. The results to be presented will therefore be based only upon measures which, usually in combination, justify some reasonable degree of confidence in their reliability and validity for the purpose in hand. Although for full details it is essential to consult the relevant papers (Heron, 1954a, 1955b ; Heron and Braithwaite, 1953), a few words may not be out of place here concerning these experimental measures of emotional instability. Each measure is based upon a subject's behaviour in a standardized task. The tasks range from the attempt to stand still with the eyes closed for one minute, to the very different situation involved in the completion of a health inventory. For a task of any type to be considered likely as a measure of emotional instability, evidence must be available that behaviour in it distinguishes significantly between contrasting groups of subjects who are, respectively, apparently stable emotionally and clearly unstable enough to have required hospital admission and treatment.

In each case comparisons will be made internally; that is, the group in question will serve as its own control. This procedure avoids the very real danger of unjustified generalizations which would attend most comparisons with external standards or norms. The necessity for this precaution should a remind us of our paucity of firm knowledge in these fields of enquiry, due partly to the intrinsic difficulties of the subject matter, partly to lack of support for the necessary research.

\section{Criteria of Occupational Adjustment}

There are two complementary aspects of occupational adjustment : the satisfaction obtained by the person occupied, and the satisfaction given by him to his 
employer (satisfactoriness). The establishment of suitable criteria for the measurement of these two aspects has occupied a considerable amount of time and energy during this programme. For the settled workers, two criteria of satisfactoriness were developed : one of these was a measure of individual productivity, very much more difficult to obtain than one is generally led to believe ; the other, a measure of the extent to which a man was a source of concern to his immediate superiors, when they were as far as possible considering this apart from productivity (Heron, 1952a). No criteria were sought in the colliery study, as this was made possible only as a piece of cooperative research with another team of investigators. The study of newly employed women factory workers used an arbitrary criterion of continuance in the job for a minimum period of six months ; in view of the dispersal to a very large number of departments, no other suitably general criterion could be established. In the study of newly employed and wholly inexperienced bus conductors, the six-months criterion period was again used, but this time because its end coincided with certain possibly significant changes in the status and emoluments of new conductors. For those men who continued beyond this criterion period, two fresh criteria were developed, one of job satisfaction and the other of "value to the employer", or satisfactoriness (Heron, 1954b).

The criterion of individual productivity mentioned above was a time-study index based upon the worker's average production over a period of 67 weeks, as obtained from shop-floor records. It appeared to be so closely related to actual output (checked for 45 men over 26 weeks on a particular type of casting) as to justify considerable confidence in its use. It may be observed here that such confidence in similar indices cannot be generally assumed; if for research purposes one must be used, it should be checked rigorously in some such manner as that described in detail in the relevant paper (Heron, 1952a).

The criterion represented by continuance in the job for a minimum period is strictly speaking a measure neither of satisfaction nor satisfactoriness, but rather a mixture of both. In so far as one can separate resignations from discharges, with confidence that the former heading does not conceal some of the latter, continuance does of course represent mainly satisfaction (provided there is something like full employment at the time). The retention of a worker for a given period can only be regarded as evidence for minimal satisfactoriness to the employer, again the level of that minimum being related to conditions affecting the firm's employment policy.

Employee satisfaction was shown in the bus conductor study (Heron, 1954b) to be composed of at least two main aspects. One is positive in nature, including such things as an intrinsic liking for the job itself-for the actual duties involved-and satisfaction with the firm as an employer. The other aspect may be described as negative, in that it is concerned with adaptation, with the acceptance of pressures: one thinks of the familiar phrase " putting up with".

In this study the "value to the employer" of men who had stayed six months was assessed by a combination of supervisory ratings (similar to those developed for the settled factory workers) with objective data about the man's behaviour obtained from office records.

\section{General Findings}

In the study of settled workers, it was possible to state clearly that, with the effects of age and experience held constant, no systematic connexion existed between intelligence level and either productivity or the extent to which a man was a source of concern to his immediate superiors. The latter criterion did, however, show a small but significant relationship with a measure of emotional instability based on a combination of four objective tests. If to this measure another was added, representing variations in men's characteristic speed of approach to a task, the relationship with supervisory concern increased significantly (Heron, 1952b). This is probably due to the fact that the criterion of concern inevitably still included a small amount of dependence on productivity in spite of the attempt to keep it out (Heron, 1952a).

With colliery workers (aged 40 to 50 ) it was found that as one proceeds within the sample studied from the office stool, through manual work on the surface, to the coal face, emotional instability (as assessed by a combination of five measures) increases significantly (Heron and Braithwaite, 1953). In the absence of satisfaction and performance criteria at each of these stages, it is not possible to state to what extent man-toman variations in emotional instability within the groups represent an occupational handicap.

Turning to the factory study of newly employed women workers, where the sole criterion was the leaving rate during the initial six months, it was necessary to exclude from further consideration 22 women who had been allocated to departments containing 100 employees or more. This was due to the fact that such departments had a significantly higher leaving rate than the smaller departments. Departments with fewer than 100 employees did not differ significantly among themselves and could therefore be considered together. This requirement reduced the total sample from 124 to 102 , the new figure consisting of 49 younger women (up to 35 years of age) and 53 older women.

In the younger group, it was found that those leaving within the first six months were as a group significantly less intelligent than those who stayed. This tendency was also evident among the older women, but did not there attain significant proportions. (Another trend which did not attain significant proportions is nevertheless worth mentioning: those who left during the first six months from the younger group tended to have (as a group) somewhat more emotionally stable scores than did those who stayed. It would be of considerable interest to have further data with which to confirm or refute this observation.)

In the last study, of new entrants as omnibus conductors, it was found that those resigning within the first six months were as a group significantly less intelligent and significantly less stable emotionally than those who 
carried on. A detailed examination of the data showed that these findings were caused mainly by those men who were, if the sample of 192 is considered as a whole, respectively the $10 \%$ least intelligent and $10 \%$ least stable. There was practically no overlap between these two extreme $10 \%$ groups. In each case the leaving rate during the first six months was almost exactly double that prevailing for the non-handicapped men. It was also found that the rate of discharge for dishonesty or aggressive behaviour tended to be higher among men identified by a test of experimentally induced stress as falling towards the extreme "extravert" end of the temperament continuum (Venables, 1953).

When attention is directed to those men, 144 in number, who stayed at least six months in the job, it can be reported that the dullest $11 \%$ were considered to be of significantly less value to their employers than were the non-handicapped in this respect. A significant association was also found between the category " unsatisfactory and dissatisfied " and the $20 \%$ least stable. A combined score for emotional stability, based on 12 measures, shows a systematic association with job satisfaction scores (Heron, 1955a).

One hundred and twenty-nine of these men were followed up for a further period of two years ; of these 12 were discharged, leaving 117 who by the end of this extended follow-up could be classed simply as " resigned " or "still employed". The Table shows the behaviour of these men as it can be related to their categories on the negative ("putting-up with") sub-score for job satisfaction.

TABLE

RESIGNATIONS ACCORDING TO CATEGORIES OF SATISFACTION

\begin{tabular}{|c|c|c|c|}
\hline Category & $\begin{array}{c}\text { Resigned } \\
\text { within } \\
\text { Two Years }\end{array}$ & $\begin{array}{c}\text { Stayed } \\
\text { Two More } \\
\text { Years }\end{array}$ & Total \\
\hline $\begin{array}{c}\text { A "Very satisfied" and } \\
\text { "Satisfied" .. }\end{array}$ & 41 & 42 & 83 \\
\hline \multirow[t]{2}{*}{ B "Very dissatisfied" .. } & 25 & 9 & 34 \\
\hline & 66 & 51 & 117 \\
\hline
\end{tabular}

$\chi^{2}=5.713, P<0.02$

The positive sub-score (active liking for the job) showed no such significant distribution. Taken together, these data therefore suggest that it is probably misleading to base predictions of employee leaving behaviour upon " global" estimates of job satisfaction ; a man may like some aspect of a job very much indeed, but, as in the present instance, it may be the things he finds " hard to put up with" that determine whether he stays in it or not.

It is important to note that during this further two years no significant associations were found between emotional instability or low intelligence and leaving behaviour. From this we may conclude that so far as this particular work is concerned, such psychological handicaps make themselves felt at once if they are going to at all. It would seem that the initial stresses of adaptation, largely social in nature, are a considerable hurdle : once surmounted, the job itself can be coped with fairly successfully.

\section{Discussion}

On the methodological side this series of studies has served to demonstrate in part what is and what is not yet possible for psychology as an applied science in the field of industrial health. Relatively objective personality measures have been given what appears to be a unique opportunity to prove their worth outside the sheltered environment of university, hospital, or military establishment. Some few of these measures have survived, one (a two-part personality inventory) has been advanced to what seems a specially useful stage (Heron, 1956a and b), but many have fallen by the wayside. Criteria of individual productivity, job satisfaction, concern to the supervisor, and general satisfactoriness to the employer have been developed ; in this connexion it seems essential to stress that such criteria of occupational adjustment must be "tailor-made" for each situation, certainly until much more first-class research has been done to indicate the extent to which such criteria have general validity.

There is now no justification for the widespread assumption that those on the borderlines of mental defect and neurosis are necessarily handicapped occupationally. Equally true, however, is the opposite : it cannot be assumed that such people will escape handicap in all circumstances. It is clearly unwise to quote reports based on settled workers as if these were valid for those newly employed. Young women workers without children or with children at school or nursery are clearly not comparable with older women coming out (or back) to work, possibly as an escape from the now-empty home. Generalizations are further in need of restraint when considerations about the inherent stresses and strains of particular work situations have to be brought into the reckoning. Finally, it is absolutely essential for us to realize that the extent to which psychological and occupational handicap are related is bound to be affected by the prevailing economic conditions. If what is called full employment were to become the norm, then the findings reported in this paper would have greater validity than can be claimed for them in times of economic uncertainty.

\section{Summary}

It will be apparent that these diverse findings are difficult to summarize, but some attempt should be made in the interests of clarity.

Those workers shown by test to be less intelligent than their fellows on the same factory job were not less productive.

Women less intelligent than their fellow new-entrants to factory work tended to be preponderant among early resignations, this being less marked among women over 35.

Among male new entrants as bus conductors, the $10 \%$ least intelligent were more likely to leave during th 
first six months, and the least intelligent of those staying so long were considered to be less satisfactory by the employers than men of average intelligence for the group.

Emotional instability among settled male factory workers was reflected as an industrial handicap only in so far as the least stable tended to be a greater source of concern to their immediate supervisors. Productivity was unaffected except by temperamental differences in speed of approach to a task.

Among male new entrants as bus conductors, the $10 \%$ least stable emotionally were more likely to leave during the first six months, and among those staying so long the least stable expressed themselves as less able than their fellows to put up with the negative aspects of the job during the early stages.

Although the conditions of the study precluded any evaluation of the effects on occupational adjustment of differences in emotional stability among older colliery workers, evidence was obtained about differences in emotional stability among various working groups within the same colliery.

\section{REFERENCES}

The techniques and findings referred to in this article are described in full detail in the following papers :-

Fraser, Russell (1947). " The Incidence of Neurosis Among Factory Workers", Rep. industr. Hlth Res. Board, Lond., Report No. 90. Heron, Alastair (1952a). "The Establishment for Research Purposes of Two Criteria of Occupational Adjustment ", Occup. Psychol., 26, 78 .

- (1952b). "A Psychological Study of Occupational Adjustment ", J. appl. Psychol., 36, 385.

(1954a). " The Objective Assessment of Personality Among Factory Workers", J. soc. Psychol., 39, 161.

(1954b). "Satisfaction and Satisfactoriness: Complementary Aspects of Occupational Adjustment", Occup. Psychol.,

28,140

955a). "Personality and Occupational Adjustment-A CrossValidation Study", Canad. J. Psychol., 9, 15.

- (1955b). "The Objective Assessment of Personality Among Female Unskilled Workers ", Educ. Psychol. Measmt, 15, 117. (1956a). "A Two-Part Personality Measure for Use as a Research Criterion." To appear in Brit. J. Psychol., 47.

(1956b). " The Effects of Real-Life Motivation on Questionnaire Response." To appear in J. appl. Psychol., 40.

- and Braithwaite, Dorothy (1953). "Emotional Stability in Colliery Workers", British Journal of Industrial Medicine, 10, 27.

Venables, Peter H. (1953). "A Study of Motor and Autonomic Responses to Experimentally-Induced Stress in an Industrial Responses to Experimentally-Induced Stress in an Industrial (1955). "Changes in Motor. Response with Increase and Decrease in Task Difficulty in Normal Industrial and Psychiatric Subjects ", Brit. J. Psychol., 46, 101. 